\title{
Assessment of risk factors for surgical complications in neonatal circumcision clinic
}

Jin Kyu Kim ${ }^{1}$; Martin A. Koyle²; Michael E. Chua ${ }^{2}$; Jessica M. Ming ${ }^{2}$; Min Joon Lee ${ }^{1}$; Amre Kesavan $^{3}$; Megan Saunders ${ }^{2}$; Joana Dos Santos ${ }^{2}$

${ }^{1}$ Faculty of Medicine, University of Toronto, Toronto, ON, Canada; ${ }^{2}$ Division of Urology, Hospital for Sick Children, Toronto, ON, Canada; ${ }^{3}$ School of Medicine, Royal College of Surgeons in Ireland, Dublin, Ireland

Cite as: Can Urol Assoc J 2018 September 27; Epub ahead of print. http://dx.doi.org/10.5489/cuaj.5460

Published online September 27, 2018

***

\section{Abstract}

Introduction: Despite the widespread use of circumcision, there is little understanding regarding risk factors associated with its complications. This investigation assesses potential risk factors contributing to complications of circumcision.

Methods: A retrospective review of all males who underwent a neonatal circumcision in our institution's pediatric urology clinic between January 2015 and June 2017 was performed. Continuous variables were dichotomized to determine a clinically relevant cutoff value. Multivariate regression analyses were used to identify risk factors for primary outcomes (early/late complications) and secondary outcomes (emergency room [ER] visitation, return to operating room [OR], post-circumcision communications).

Results: A total of 277 patients were identified. The mean age and weight were 28.4 days and $4.3 \mathrm{~kg}$, respectively; $93.1 \%$ of cases were elective and $12.3 \%$ of patients had comorbidities. Circumcisions were performed using Mogen (61.4\%) or Gomco clamps (39.6\%) under local anesthesia. Overall, 35 patients experienced complications (12.6\%). There were 18 patients (6.5\%) with bleeding requiring sutures at time of circumcision. Twenty-six patients (9.4\%) experienced long-term complications, with penile adhesions being the majority (84.6\%). One $(0.4 \%)$ of these patients had a Clavien-Dindo 3 complication requiring surgery for a skin bridge that could not be separated. One patient $(0.4 \%)$ visited the ER due to postoperative bleeding from the circumcised area, which was managed conservatively. Multivariate regression analysis identified weight $>5.1 \mathrm{~kg}$ a risk factor for bleeding requiring sutures (odds ratio [OR] 4.145; 95\% confidence interval [CI] 1.246-13.799) and long-term complications (OR 3.738; 95\% CI 1.35610.306). No risk factors were identified for other outcomes (return to OR, ER visitation, postcircumcision email/telephone communications). 
Conclusions: This investigation of neonatal circumcision revealed that patients weighing $>5.1$ kg may be at higher risk of bleeding and long-term complications, such as adhesions.

\section{Introduction}

Approximately one-third of males are circumcised worldwide, making circumcision one of the most common urological procedures. ${ }^{1}$ The majority of these males undergo circumcision as an infant and it is performed on an elective basis due to cultural, religious, or other reasons. ${ }^{2}$ As with all urological procedures, it carries risks including early complications such as bleeding or inadequate (and/or excessive) skin removal, as well as late, such as penile adhesions or meatal stenosis. ${ }^{2,3}$ More serious complications such as infection, amputation, and rarely, death can also occur. ${ }^{4,5}$ With more than 1 million male newborns in the US and greater than $30 \%$ of Canadian male newborns being circumcised annually, it is important to understand the potential complications and their risk factors to properly inform families, prepare adequately and ultimately, avoid stress for families while also reducing healthcare costs incurred by an elective procedure. ${ }^{6-8}$

Our institution is one of a few centers in Canada that offers neonatal circumcision services to the general population for both elective (religious, cultural, and/or parental preference) and medically indicated circumcision. In our clinic, circumcisions are performed by pediatric urologists or by a medical urologist, a pediatrician who focuses on clinical, rather than surgical, management of urological conditions. Therefore, this study aims to assess the rates of complications in a neonatal clinic while evaluating the risk factors for such complications.

\section{Methods}

This project was approved by the institutional research ethics board (REB \# 1000058350). A retrospective chart review was performed to assess all patients who underwent a neonatal circumcision since the clinic's first procedure in January 2015 to June 2017. Clinic circumcisions were offered to healthy male neonates under 8 weeks of age (corrected for prematurity/ gestational age) with no significant comorbidities that would deter clinic procedure.

All patients undergoing elective circumcisions were brought by parents who discovered the clinic through their own means (e.g. internet advertisements). The patients who underwent medically indicated circumcision were those who were seen at our institution's pediatric urology clinic and referred to the neonatal circumcision clinic. The clinic process, briefly, included a preliminary evaluation by the physician reviewing the birth history and urology clinic nurse reviewing lab work and evaluating for any penile abnormalities. If any of these were found, the performing provider determined whether the procedure would take place in clinic or needed further intervention in the operating theater. If adequate, the urology nurse applied Lidocaine $4 \%$ cream to the penile area which was left in place for 20 to 30 minutes. Every boy then received a penile block (dorsal or ring) and oral Acetaminophen $15 \mathrm{mg} / \mathrm{kg}$ and oral sucrose for further analgesia. Circumcision was performed using either a Mogen or Gomco clamp, based on provider preference. Every patient was observed in clinic for at least 20 minutes after the 
procedure to monitor for postoperative bleeding. If ongoing bleeding, octyl cyanoacrylate (Dermabond ${ }^{\circledR}$ ) was used as an initial attempt to stop the bleeding. If unsuccessful, chromic 5-0 or 6-0 interrupted sutures were used to stop the bleeding under local anesthesia. All clinic information and discharge instructions were reviewed prior to patient discharge and parents were provided education on post-circumcision care. For prevention of post-circumcision adhesions, parents were instructed to start retracting foreskin off the edge of the glans starting postcircumcision day 3 , while applying petroleum jelly cream/ointment to act as a protective barrier for fecal material from entering the site of circumcision. Parents were further instructed to gently wash any fecal materials that enter the circumcision site using mild soap and water. Parents were further advised to visit their primary care physician or pediatrician in 1-3 months following circumcision.

There was no specific follow up arranged for the circumcised patients. However, parents are given a brochure outlining potential complications from the circumcision and what the concerning presentations are. Parents are provided the telephone/email communication means to contact our urology nursing staff with questions or concerns following circumcision. Otherwise, the floor coordinator and/or urology nurse will call/email the family one week following circumcision to inquire regarding post-circumcision condition. Depending on the presentation at the time of the first communication, a second communication will be made at two weeks following circumcision. If any concerns during these communications arise, they are followed up in our urology clinic or are referred back to the urology clinic by the primary care physicians or pediatricians.

The list of patients was generated using the clinic records. Patients' electronic patient charts were referred to for details regarding: patient's age (corrected for prematurity/gestational age) at time of procedure, weight, circumcision technique used, co-morbidities, indications for circumcision, early complications (defined as complications occurring during or postcircumcision, prior to discharge), long-term complications (defined as complications occurring $>24$ hours following circumcision), and post-circumcision surgical intervention. Other outcomes including emergency department (ER) visitation and post-circumcision communications were also collected.

Primary outcomes for this study were: (1) early complications and (2) long-term complications. Secondary outcomes explored were: post-circumcision surgical intervention, ER visitation, and post-circumcision communications. Only those complications that were identified in follow-up were included for analysis. All post-circumcision complications were assessed first by urology nurses and counter-checked by pediatric urologists when issues are recognized by communications (email, telephone), visit to ER, and return to clinic.

Collected data was assessed to identify potential risk factors that could affect clinical outcomes. Age and weight were dichotomized to determine a clinically relevant cut-off value, which was determined as one standard deviation above the overall mean value. The dichotomization was determined a priori to identify a subset of patients above the $84^{\text {th }}$ percentile 
for age and weight in our specific cohort. All variables' adjusted effect estimates were assessed by multivariable regression analysis. Statistics were performed using the Statistical Package for Social Sciences (SPSS) Software (Version 20.0.0) with assumed two-sided alternative hypothesis and level of significance at 0.05 .

\section{Results}

A total of 277 patients who underwent circumcision at our institution's neonatal circumcision clinic were identified. Most patients (95.7\%) were less than 60 days old with a mean age of 28.4 days (range 3 -108). The mean weight was 4.3 kilograms (range 2.2 - 6.8). Most patients were undergoing circumcision electively, without medical indication (93.1\%). The medical indication for circumcision in our cohort was recurrent urinary tract infections in context of refluxing ureteral units. Co-morbidities at baseline (prior to circumcision) were found in $12.3 \%$ of patients. Of these patients, $14.7 \%$ had penile and urethral anomalies (hypospadias, buried penis, penoscrotal webbing, megameatus), 50.0\% had other urological conditions involving kidneys, ureters, or bladder (hydronephrosis, hydroureter, renal dysplasia, chronic kidney disease, neurogenic bladder, vesicoureteral reflux), and $44.1 \%$ had co-morbidities unrelated to kidneys, ureters, or bladder (congenital heart disease, spina bifida, cortical injury/infarcts, hyperbilirubinemia, lymphatic malformations, duodenal atresia, imperforate anus, polycythemia, umbilical hernia, hypothyroidism; Table 1).

All circumcisions were performed using Gomco or Mogen clamps and under local anesthesia in the neonatal circumcision clinic. The Mogen clamp was used in $61.4 \%$ of patients and $39.6 \%$ of patients were circumcised using the Gomco clamp.

Overall, 35 patients (12.6\%) experienced complications. With regards to our primary outcome of early complications, there were 18 patients (6.5\%) with post-procedural bleeding that required suturing. There were 62 patients (22.4\%) who required the use of octyl cyanoacrylate (Dermabond $\AA$ ) who did not require sutures. There were no other early complications noted. Twenty-six patients (9.4\%) had our second primary outcome of long-term complications, with the majority of them being penile adhesions (84.6\%). Only $1(0.4 \%)$ of these complications required operative intervention due to a bridge that could not be separated. One patient $(0.4 \%)$ visited the ER due to post-operative bleeding from the circumcised area requiring suturing (Table 2).

The weight and age were dichotomized into age $>52$ days and weight $>5.1$ kilograms. Both were included in the multivariate regression. A weight over 5.1 kilograms was identified as a risk factor for both bleeding requiring sutures (OR 4.145, 95\% CI 1.246-13.799; Table 3) and for long-term complications (OR 3.738, 95\% CI 1.356-10.306; Table 4). For all other outcome measures (complications requiring surgical intervention, ER visitation, e-mail/telephone communication), none of the factors assessed were identified as risk factors. 


\section{Discussion}

Although there have been many attempts to identify rates of post-circumcision complications, there is still limited data on potential risk factors for complications of neonatal circumcision. ${ }^{9,10}$ Costs of circumcision-related complications are significant; according to a study from Massachusetts General Hospital, the annual cost of such complications were greater than $\$ 100,000 .^{7}$ In a resource limited publicly funded healthcare system such as Canada, it is imperative to identify and minimize risk factors that contribute to these complications. In Canada, provincial health insurance covers for medically indicated procedures. Therefore, any unforeseen complications in patients undergoing circumcision will incur costs to the healthcare system, especially if complications involved ER visitations and return to OR. Therefore, this study aimed to assess these factors by evaluating 277 consecutive cases of circumcision in one of the only neonatal circumcision clinics operated by pediatric urologists in Canada.

The rates of complication for neonatal/infant circumcision, reported by prospective studies, vary greatly with rates as low as $0 \%$ and as high as $16 \%{ }^{2,11-18}$ Rates differed depending on the technique used, the means of reporting adverse outcomes since some opted to report only serious complications, and the length of follow-up with less complications for the shorter followup times. The only short-term complication that occurred in our series was bleeding which occurred in $6.5 \%$ of patients, all of which were managed in the clinic with sutures and/or octyl cyanoacrylate (Dermabond $®$ ). The bleeding rates reported in our series of patients is high compared to those reported previously for neonatal circumcision. ${ }^{11,19}$ Banieghbal reported only 2 bleeding complications requiring sutures in 583 infants less than 5 weeks old by employing Gomco clamp method and Horowitz et al. similarly had no complications in 98 patients in first month of life by also employing the Gomco clamp method. Plank et al. reports bleeding outcomes following Mogen clamp use at 3.2\%, which is still lower than seen in this investigation. ${ }^{20}$

Overall, 9.4\% of all circumcised neonates had long-term complications with the majority of these being adhesions. However, of these children, only $1(0.4 \%)$ required surgical intervention while all others were managed conservatively with observation or medically, using betamethasone cream. There were no serious adverse events, which is consistent with most previous investigations that have low rates of $0-2.1 \% \cdot{ }^{2,11-17}$ Furthermore, prospective studies may also report better outcomes due to increased efforts to achieve best outcomes by participating healthcare practitioners. Most of these studies also do not assess the Mogen clamp technique, which was used in greater than half of our study population. Therefore, due to the inconsistency in means of reporting and definition of adverse events, it is difficult to make an accurate comparison and conclusion regarding circumcision complication rates.

This investigation identified weight as a risk factor for bleeding requiring sutures. For both the Gomco and Mogen clamp techniques, tightening of clamps may aid in hemostasis while the foreskin is removed. ${ }^{4}$ However, it is possible that heavier patients may have thicker keratin that leads to inadequate sealing of the wound and consequent bleeding. This finding is supported 
by previous findings that showed a higher likelihood of bleeding complications in infants aged $>3$ months compared to neonates, since older boys may also have thicker keratin compared to younger boys. ${ }^{11}$ Although our study did not identify age as a risk factor for bleeding, we only assessed neonates with mean age of 28.4 days. Future studies assessing both neonatal and older age groups may further elucidate whether our hypothesis of factors leading to thicker keratin being risk factors for bleeding.

This study also found weight over 5.1 kilograms to be a risk factor for long-term complications, most notably adhesions. Given that skin migration from a suprapubic fat pad can contribute to adhesion formation, our findings may be explained by more prominent suprapubic fat pads burying the penis and promoting adhesion formation. This is consistent with previous findings by Williams et al. that reported that majority of patients requiring circumcision revision had prominent suprapubic fat pads. ${ }^{21}$ In terms of clinical significance, only $0.4 \%$ of these patients required surgical intervention, suggesting low proportions of "clinically significant" complications. However, this study still provides data that describes the natural history of circumcision that can be useful in guiding practitioners and authors of future guidelines, especially due to circumcision being one of the most common procedures being performed in North America - although difficult to generalize, according to our data, approximately 4,000 patients in US alone could experience such "clinically significant" complications every year that could have been avoided by being cognizant of risk factors being given extra caution.

As a retrospective study, this study carries the potential for sampling bias; this was minimized by including all patients who underwent circumcision in the clinic during the study period. There is also possibility of confounding and presence of unmeasured risk factors that are present due to the study's retrospective nature. Moreover, there was no planned long-term follow up for this study and it is difficult to assess the extent of long-term complications such as meatal stenosis that may occur years after circumcision. ${ }^{22}$ Hence, future directions following this study would be to have a longer follow-up period, which was difficult due to the recent establishment of our neonatal circumcision clinic in 2015. Given that all of our patients underwent either Gomco or Mogen clamp as a means of circumcision, the results of this study may not be generalizable to practitioners, including obstetricians, pediatricians and trained nurse practitioners, who employ other methods of circumcision. However, in our population, a pediatrician performed $39.6 \%$ of the circumcision using a Gomco clamp, a tool that is widely used by community pediatricians and obstetricians for neonatal circumcision and this may add to the study's generalizability. Furthermore, although our study identified a risk factor for complications, there was no cost-analysis and it is difficult to ascertain whether certain benefits of circumcision will outweigh the potential risks for complications in the lifetime of the patient. As more evidence behind potential benefits and risks regarding circumcision are presented in the future, a specific cost-analysis should be considered to determine not only the health benefits and risks but societal benefits and risks of circumcision. 
To our knowledge, this is the first study suggesting weight as a risk factor for bleeding. Moreover, this study is also the first to propose a cut-off value that increases the risks of bleeding and long-term complications. Although many studies have assessed for rates of complications in the past for other methods, this is one of the few studies that assesses the complication rates involving the Mogen technique. Because neonatal circumcision clinic is a unique service available to few patients in North America, the results of the study may not seem generalizable to most patients. However, anatomical principles that may explain the results of this study can be applied to most newborn males. Moreover, given that complications of circumcision are a large burden on both costs of healthcare and stress of the patients' families, the findings of this investigation may allow better preparation by healthcare professionals for neonates at higher risk and consequently reducing the sequelae of complications. Furthermore, this data may also allow healthcare practitioners to fully inform families of risks of complication prior to circumcision procedures. Although preliminary, the current findings can be useful for future clinical practice guidelines for circumcision, as a weight of $5.1 \mathrm{~kg}$ or greater, appears to be a clear cut-off that may portend a higher potential for complications. It is therefore incumbent on the provider who is to perform the circumcision, to weigh the risks, and discuss options, with the parents of these boys in order to confirm the appropriate timing and setting for the circumcision. Moreover, the series of patients observed in this study revealed a higher incidence of bleeding complications compared to previously reported outcomes, despite the circumcisions being performed at a surgical specialty clinic. Whether this occurrence rate is due to a small sample size or this rate is maintained with further experience and larger volumes, requires further study on our part. Regardless of presumed expertise, it is imperative that whoever performs circumcision must be aware that complications do arise, and ideally a setting must be available that is able to deal with them accordingly. Although the potential decreasing risk by improving technique would be less less likely, one must ensure that all healthcare practitioners performing circumcision to be proficient with the clamps. Thus, it would be recommended that healthcare providers acknowledge that heavier infants may be at higher risk for post-circumcision complications and should be anticipated and prepared and may orient the parents about the higher chance of complications as we described. Future prospective studies assessing the risk factors would be valuable in reducing rates of circumcision complications while confirming weight as a risk factor.

\section{Conclusion}

The assessment of 277 patients undergoing circumcision in a neonatal clinic showed that the rates of complications were low with no clinically significant adverse events. Patients weighing more than 5.1 kilograms may be at higher risk of bleeding and long-term complications such as adhesions. 


\section{References}

1. WHO/UNAIDS. Male circumcision: global trends and determinants of prevalence, safety and acceptability. World Heal Organ 2008:7.

2. Weiss HA, Larke N, Halperin D, Schenker I. Complications of circumcision in male neonates, infants and children: a systematic review. BMC Urol 2010;10(2):1-13.

3. American Academy of Pediatrics. Circumcision Policy Statement. Pediatrics 2012;130:585-586.

4. Krill AJ, Palmer LS, Palmer JS. Complications of Circumcision. Sci World J 2011;11:2458-2468.

5. Brook I. Infectious Complications of Circumcision and Their Prevention. Eur Urol Focus 2016;2(4):453-459.

6. Agency for Healthcare and Research Quality. Circumcision Rates Highest In Midwest, Lowest in West. AHRQ News and Numbers. https://www.ahrq.gov/. Published 2008.

7. $\quad$ Pieretti R V., Goldstein AM, Pieretti-Vanmarcke R. Late complications of newborn circumcision: A common and avoidable problem. Pediatr Surg Int 2010;26(5):515-518.

8. Sorokan ST, Finlay JC, Jefferies AL. Newborn male circumcision. Paediatr Child Heal 2015;20(6):311-315.

9. Abara EO. Prepuce health and childhood circumcision: Choices in Canada. Can Urol Assoc J 2017;11(1-2S):55.

10. Srinivasan M, Hamvas C, Coplen D. Rates of Complications After Newborn Circumcision in a Well-Baby Nursery, Special Care Nursery, and Neonatal Intensive Care Unit. Clin Pediatr (Phila) 2015:1-7.

11. Horowitz M, Gershbein AB. Gomco circumcision: When is it safe? J Pediatr Surg 2001;36(7):1047-1049.

12. Patel H. The problem of routine circumcision. Can Med Assoc J 1966;95(11):576-581.

13. Perlmutter DF, Lawrence JM, Krauss AN, Auld PA. Voiding after neonatal circumcision. Pediatrics 1995;96(6):1111-1112.

14. Palit V, Menebhi DK, Taylor I, Young M, Elmasry Y, Shah T. A unique service in UK delivering Plastibell(R) circumcision: Review of 9-year results. Pediatr Surg Int 2007;23(1):45-48.

15. Mousavi SA, Salehifar E. Circumcision complications associated with the Plastibell device and conventional dissection surgery: a trial of 586 infants of ages up to 12 months. Adv Urol 2008;2008(January):606123.

16. Osuigwe A, Ikechebelu J, Okafor P. Circumcision-Related Complications in the Male: Experience amongst the Igbo's of Southeast Nigeria. African J Urol 2005;10(4):246-251.

17. Okafor P, Orakwe J, Osuigwe A, Chianakwana G. Experience With Immediate Postpartum Circumcision. Nigerian Medical Practitioner. Niger Med Pract 2005;47:9-11.

18. Bowa K, Li MS, Mugisa B, et al. A controlled trial of three methods for neonatal circumcision in Lusaka, Zambia. J Acquir Immune Defic Syndr 2013;62(1):e1-6.

19. Banieghbal B. Optimal time for neonatal circumcision: An observation-based study. $J$ Pediatr Urol 2009;5(5):359-362.

20. Plank RM, Ndubuka NO, Wirth KE, et al. A randomized trial of mogen clamp versus plastibell for neonatal male circumcision in Botswana. J Acquir Immune Defic Syndr 2013;62(5). 
21. Williams CP, Richardson BG, Bukowski TP. Importance of identifying the inconspicuous penis: Prevention of circumcision complications. Urology 2000;56(1):140-143.

22. Frisch M, Simonsen J. Cultural background, non-therapeutic circumcision and the risk of meatal stenosis and other urethral stricture disease: Two nationwide register-based cohort studies in Denmark 1977-2013. Surgeon 2018;16(2):107-118. 
Figures and Tables

\begin{tabular}{|l|c|}
\hline \multicolumn{2}{|l|}{ Table 1. Baseline characteristics of study population } \\
\hline Characteristic & All patients (n=277) \\
\hline & $\mathrm{n}(\%)$, mean (SD) \\
\hline Age (days) & $28.4(17.6)$ \\
\hline Weight (kg) & $4.3(4.1)$ \\
\hline Elective & $258(93.1)$ \\
\hline Medically indicated & $19(6.9)$ \\
\hline Patients with comorbidities* & $34(12.3)$ \\
\hline $\begin{array}{l}\text { Penile and urethral } \\
\text { anomalies }\end{array}$ & $5(14.7)$ \\
\hline Other urological conditions & $17(50.0)$ \\
\hline Non-urological conditions & $15(44.1)$ \\
\hline
\end{tabular}

*Total number of comorbidities listed below is not equal to $100 \%$ because some patients had $>1$ complications. SD: standard deviation.

\begin{tabular}{|c|c|}
\hline Technique & All patients $(n=277)$ \\
\hline & n (\%), mean (SD) \\
\hline Mogen clamp & $170(61.4)$ \\
\hline Gomco clamp & $107(39.6)$ \\
\hline Complications & \\
\hline Bleeding requiring sutures & $18(6.5)$ \\
\hline $\begin{array}{l}\text { Patients with long-term } \\
\text { complications* }\end{array}$ & $26(9.4)$ \\
\hline Adhesions & $22(84.6)$ \\
\hline Excess skin & $4(15.4)$ \\
\hline Phimosis & $2(7.7)$ \\
\hline $\begin{array}{l}\text { Complications requiring } \\
\text { surgical intervention }\end{array}$ & $1(0.4)$ \\
\hline Excess skin & $1(100.0)$ \\
\hline Return to ER & $1(0.4)$ \\
\hline Bleeding & $1(100.0)$ \\
\hline
\end{tabular}

*Total number of complications listed below is not equal to $100 \%$ because some patients had $>1$ complications. ER: emergency room; SD: standard deviation. 


\begin{tabular}{|l|c|c|c|c|}
\hline Table 3. Characteristics of patients with bleeding requiring sutures \\
\hline Characteristics & $\begin{array}{c}\text { Patients with } \\
\text { bleeding } \\
\text { requiring sutures } \\
\text { (n=18) }\end{array}$ & $\begin{array}{c}\text { Patients not } \\
\text { requiring } \\
\text { sutures for } \\
\text { bleeding (n=259) }\end{array}$ & $\mathbf{p}$ & $\begin{array}{c}\text { Odds ratio } \\
\text { (95\% CI) }\end{array}$ \\
\hline Age >52 days & $\mathrm{n}$ (\%), mean (SD) & $\mathrm{n}$ (\%), mean (SD) & & \\
\hline Weight $>5.1 \mathrm{~kg}$ & $5(27.8)$ & $29(11.2)$ & 0.561 & $\begin{array}{c}1.486 \\
(0.391-5.640)\end{array}$ \\
\hline $\begin{array}{l}\text { Medically indicated } \\
\text { (compared to elective) }\end{array}$ & $3(44.4)$ & $36(13.9)$ & $0.020^{*}$ & $\begin{array}{c}4.145 \\
(1.246-13.799)\end{array}$ \\
\hline Comorbidity & $5(27.8)$ & $29(11.3)$ & 0.127 & $\begin{array}{c}1.333 \\
(0.218-8.152)\end{array}$ \\
\hline $\begin{array}{l}\text { Mogen clamp } \\
\text { (compared to Gomco } \\
\text { clamp) }\end{array}$ & $9(50.0)$ & $161(62.2)$ & 0.258 & $0.732-12.221)$ \\
\hline
\end{tabular}

CI: confidence interval; SD: standard deviation.

\begin{tabular}{|l|c|c|c|c|}
\hline Table 4. Characteristics of patients with long-term complications \\
\hline Characteristics & $\begin{array}{c}\text { Patients with } \\
\text { long-term } \\
\text { complications } \\
\text { (n=26) }\end{array}$ & $\begin{array}{c}\text { Patients without } \\
\text { long-term } \\
\text { complications } \\
\text { (n=251) }\end{array}$ & $\mathbf{p}$ & $\begin{array}{c}\text { Odds ratio } \\
\text { (95\% CI) }\end{array}$ \\
\hline Age $>52$ days & $5(19.2)$ & $29(11.6)$ & 0.879 & $\begin{array}{c}0.911 \\
(0.272-3.044)\end{array}$ \\
\hline Weight $>5.1 \mathrm{~kg}$ & $9(34.6)$ & $35(13.9)$ & $0.011^{*}$ & $\begin{array}{c}3.738 \\
(1.356-10.306)\end{array}$ \\
\hline $\begin{array}{l}\text { Medically indicated } \\
\text { (compared to } \\
\text { elective) }\end{array}$ & $1(3.8)$ & $18(7.2)$ & 0.435 & 0.398 \\
\hline $\begin{array}{l}\text { Comorbidity } \\
\text { n (\%), mean (SD) }\end{array}$ & & & $(0.039-4.020)$ \\
\hline $\begin{array}{l}\text { Mogen clamp } \\
\text { (compared to Gomco } \\
\text { clamp) }\end{array}$ & $2(7.7)$ & $32(12.7)$ & 0.689 & 0.714 \\
\hline
\end{tabular}

CI: confidence interval; SD: standard deviation. 